\title{
Combined use of the llizarov non-free bone plasty and Masquelet technique in patients with acquired bone defects and pseudarthrosis
}

\author{
D.Yu. Borzunov ${ }^{1,2}$, D.S. Mokhovikov ${ }^{3}$, S.N. Kolchin ${ }^{3}$, E.N. Gorbach ${ }^{3}$ \\ ${ }^{1}$ Ural State Medical University, Ekaterinburg, Russian Federation \\ ${ }^{2}$ Central City Clinical Hospital, Ekaterinburg, Russian Federation \\ ${ }^{3}$ Ilizarov National Medical Research Centre for Traumatology and Orthopedics, Kurgan, Russian Federation
}

\begin{abstract}
Introduction The Masquelet induced membrane technique is effective in the management of acquired heterogeneous long bone defects and pseudarthrosis. The combination of the Masquelet technology and Ilizarov non-free bone grafting seems promising and reduces the risks of recurrence at long-term in patients with congenital pseudarthrosis. Purpose Presentation of new technological solutions that allow combining the advantages of the Ilizarov bone transport and Masquelet bone grafting in patients with acquired bone defects. Materials and methods Retrospective assessment of the results of bone reconstruction in 10 patients who were treated by a combination of Ilizarov and Masquelet bone grafting technologies to repair long bone defects after failures of previous treatment. Fragments of the biomembrane formed around the cement spacer temporarily replacing the tibial gap after resection bone defect or pseudarthrosis were examined in all patients. The studies were carried out using a Reichard sledge microtome, an AxioScope stereomicroscope and an AxioCam ICc 5 digital camera, a JSM-840 scanning electron microscope and an INCA-200 Energy X-ray electron probe microanalyzer. Results and discussion The combined Masquelet technique and Ilizarov non-free bone plasty provide the conditions that are favorable for reparative processes of the transported fragments. After removal of the spacer, there is a tunnel formed in the interfragmental gap, the walls of which are made of the induced membrane. Bone transport is carried out without technical problems through the compromised tissues which are debrided at the time of distraction initiation, outside the scars. At the same time, there are low risks of inflammation around the transosseous elements; there is no danger of cutting and perforation of soft tissues by transported fragments. Conclusions Complete organotypic rearrangement of the distraction regenerate with the use of Ilizarov non-free bone plasty and the Masquelet technique excludes the possibility of deformities or fractures at the level of newly formed bone areas. Active distraction histogenesis ensures the closure of soft tissue defects without additional reconstructive plastic interventions. The revealed dependence of the induced membrane blood supply on the method of treatment previously used might be a criterion for predicting the treatment outcome in patients with acquired bone defects and pseudarthrosis.
\end{abstract}

Keywords: Ilizarov method, Masquelet method, bone defect, pseudarthrosis, induced membrane

\section{INTRODUCTION}

The induced membrane technique (IMT) in combination with a cancellous autogenous grafting was proposed by Masquelet in 1986 and has been used lately for management of acquired heterogenous long bone defects and pseudartrosis formed due to resection and radiation therapy in primary bone tumours, injuries and their sequelae, including the infected ones and presence of active osteomyelitic process [1]. Our experience was successful management of congenital tibial pseudarthrosis with the combination of IMT and transosseous osteosynthesis [2]. The technology was modelled in the experiment on dogs $[3,4]$. The combination of IMT and Ilizarov non-free bone plasty seems a promising solution which may reduce the recurrence risk of refracture in the long term in patients with congenital tibial pseudarthrosis.

Prior studies gave preference to external fixators for osteosynthesis when applying the Masquelet technique. External fixation as a system for fixation and stabilization of bone fragments was judged as the one that decreases the quality of life if applied for a long time to provide treatment tasks and bone remodelling. At present, intramedullary fixators have been preferred for osteosynthesis in IMT application $[1,5,6]$. However, there is no unified approval of the Masquelet technique as the analytical review of available literature shows and there are studies that doubt its efficacy and results [7].

Some drawbacks of the transosseous osteosynthesis, and, first of all, lower patients' quality of life, long multistaged management, risks of soft-tissue infection around the transosseous elements and possible joint contractures restrict its use and are well known [8-10].

The comparative study of Mi M. et al [11] that included the Ilizarov non-free bone plasty (37 sources) and the Masquelet technique (41 sources) did not find statistical differences and reliable advantages between 
them in regard to consolidation, bone deformities, infection risks and failures that ended with amputation. However, the patients treated with the Masquelet technique had refractures 8.5 times more frequent than by the use of the Ilizarov bone plasty. It might be associated with the fact that massive free grafts need a long time for bone remodelling, including under the conditions of the induced membrane.
We aimed to trial a new technological solution and combined the merits of the Ilizarov bone transport and Masquelet technique for management of patients with acquired bone defects.

While developing the combined technology, we considered the critical opinions of our colleagues about specific shortcomings and risks of the Ilizarov bone transport and the Masquelet technology.

\section{MATERIAL AND METHODS}

We retrospectively studied the treatment results in 10 patients with long bone defects managed by the combined technology involving the Ilizarov bone plasty and the Masquelet technology.

The patients were treated at one and the same department of the Ilizarov Centre in 2016-2019. There were two females and eight males aged from 27 to 62 years. All the defects were post-traumatic due to trafic accidents in eight cases, home trauma in one and injury at the production site in one more. Time since injury was from one to seven years (mean, $3.7 \pm 1.5$ ). Previous treatment had failed in all of them, and three patients had had multiple surgeries. The anamnesis and medical documentation available revealed that four patients had locked intramedullary osteosyntheis, plating was used in five, and eight had tried transosseous osteosynthesis. Soft tissues were changed due to scars and adhesions to bone resulting from injuries and previous surgeries. Four patients had femoral defects and pseudarthrosis, four tibial nonunions. One female patient had a $7-\mathrm{cm}$ defect of the humerus and one patient a $5-\mathrm{cm}$ defect of the ulna.

Nonunions were classified according to Karger C. et all. [10]. One patient had defect of class I $(<2 \mathrm{~cm})$. Four cases were defects of class II $(2-5 \mathrm{~cm})$ and class III defects $(5-10 \mathrm{~cm})$ were detected in five cases. There were no defects of class IV $(>10 \mathrm{~cm})$. According to V.I. Shevtsov et al classification [13], the nonunons were of defect-pseudarthrosis types with anatomical shortening (6 patients) and without limb shortening in one case. Defects with gaps and anatomical shortening were revealed in two patients and one did not have anatomical shortening. Thus, the anatomical shortening ranged from one to $7 \mathrm{~cm}$ (mean, $4.6 \pm 2.2$ ).

Fragments of the biomembrane formed around the cement spacer temporarily replacing the tibial gap after resection bone defect or pseudarthrosis were examined in all patients. The material was collected intraoperatively. The tissue fragments were fixed in $10 \%$ of neutral formalin, decalcified in a mixture of chloric and formic acids, and dehydrited in ethanol in ascending concentrations and poured into paraffin.

The histological sections were prepared using a sledge microtome (Reichard, Germany), then stained with hematotoxilin and eosin according to Masson and also were stained immunohistochemically with polyclonal antiibodies to osteopontin according to the Abcam protocol and kits (Abcam, England).

AxioScope stereomicroscope and an AxioCam ICc 5 digital camera were used for light microscopy in a complex with Zen Blue software (Carl Zeiss MicroImaging GmbH, Germany).

The distribution of $\mathrm{Ca}$ in the biomembrane was studied with a scanning electron microscope JSM840 (Japan) and an INCA-200 Energy X-ray electron probe microanalyzer (Oxford Instruments, England).

\section{RESULTS}

Osteosynthesis technology The Masquelet technique implies two stages. Correspondingly, its combined technology with the Ilizarov bone transport included two surgical interventions. At the first stage, radical debridement of soft tissues and bone in the defect area was realized [14]. Next, a polymethylmetacrylate cement spacer was implanted into the interfragmental gap. The spacer had similar diameter as the adjacent bone and its volume corresponded to the gap. The literature describes that the spacer should go beyond the bone end by $2-3 \mathrm{~cm}$ in order to form a continuous induced membrane over to the periosteum
[6]. We did not follow this recommendation. The spacers were shaped as interfragmental cylinders and were from 3 to $6 \mathrm{~cm}$ long (mean, $4.2 \pm 1.1 \mathrm{~cm}$ ), one dose of gentamycin and vancomycin was added. The segment was fixed in the Ilizarov fixator in our type of operation. Its assembly provided further performance of osteotomy for bone transport.

As according to Masquelet, the cement spacer is removed after 6-8 weeks and the defect is filled in with a cancellous graft. In its deficit, implantation materials are added. The segment is fixed with an internal metal fixator or external fixator [14]. 
In our design of operations, the spacer was removed after 3-5 weeks. Duration of spacer implantation was from 26 to 45 days (mean, $37.9 \pm 4.9$ days). A large difference in time between the stages was due to outpatient stay of patients living in the remote regions of Russia and due to organizational issues. Upon spacer removal and wound stitching, osteotomy of one fragment or fragments was performed. Corticotomy was prefered for breaking the bone. For the defect of more than $4-5 \mathrm{~cm}$, we recommend osteotomy (corticotomy) of both fragments in order to shape bifocal regeneration [15] but this technology was not used for acquired defects, only one-level lengthening of the fragment was used. However, we have reported on the technology of multilevel lengtening of tibial fragments combined with the Masquelet technique for congenital tibial pseudarthrosis [2]. Distraction was initiated on days 5 to 7 after the operation. The rate of fragment transport was $0.75-1.0 \mathrm{~mm}$ a day and depended on the activity of distraction osteogenesis. Control of bone formation was conducted with radiography. Duration of transport continued $47.3 \pm 9.8$ days. Due to radical character of surgical treatment of the fragments' ends and absence of end plates, closed reduction and coaptation was used. Compression was maintained at the junction of the fragments with $1.00 \mathrm{~mm}$ once every 10-14 days untill consolidation. Mean fixation in the Ilizarov fixator was $185.4 \pm 6.6$ days. Residual anatomical shortening at follow-ups measured from one to $6.0 \mathrm{~cm}$ in three patients (mean, $3.3 \pm 1.8 \mathrm{~cm}$ ).

A soft-tissue sheath, $1.5-2.5 \mathrm{~mm}$ thick and of structured organization, was formed by the moment of spacer removal in all the patients. It was a loose fiber connective tissue with a moderate or abundant content of microvessels which volumetric density varied from 103.3 to 342.6 per $1 \mathrm{~cm}^{2}$ (Table 1). The internal to the spacer layer consisting of one to 3 rows of the basal layer cells acquired red colour when stained according to Masson (Fig. 1 a) and by immunohistochemical reaction showed a medium and intensive expression of osteopontin in its cells (Fig. 1 b). The external layer contained a considerable number of microvessels (Fig. 1 a), which perivascular cells also revealed an osteopontin-positive reaction (Fig. 1 b). There was a weak PAS-positive staining round some cells of the basal and inner part of the external layer (Fig. $1 \mathrm{c}$ ) that proves the presence of cyaloglycoproteins that participate in the formation of bone matrix. Calcium contents of $0.3-0.7$ weight $\%$ also confirm the osteogenic potential of the membrane formed. Electronic mapping of distribution in characteristic roentgenic radiation of $\mathrm{Ca}$, its maximum content was visualized in the perivascular spaces (Fig. 2 a).

Table 1

Numeric density of biomembrane microvessels in the patients with different methods of primary treatment

\begin{tabular}{|l|c|}
\hline \multicolumn{1}{|c|}{$\begin{array}{c}\text { Method of previous } \\
\text { treatment }\end{array}$} & $\begin{array}{c}\text { Numeric density of } \\
\text { microvessels in } 1 \mathrm{~cm}^{2} \\
(\mathrm{M} \pm \mathrm{m})\end{array}$ \\
\hline Intramedullary nailing & $282 \pm 9.4^{*}$ \\
\hline $\begin{array}{l}\text { Transosseous } \\
\text { osteosynthesis }\end{array}$ & $331 \pm 11.6^{*}$ \\
\hline Plating & $107 \pm 3.7^{*}$ \\
\hline$*-\mathrm{p} \leq 0.05-$ when compared with other treatment method
\end{tabular}

The study of the numeric density of microvessels showed that the biomembrane blood supply did not significantly depended on age, segment and even defect class. There was an expressed dependence of vascularity of the newly formed periosteum-like membrane on the method of previous treatment for restoring bone integrity. The least number of vessels in the biomembrane was found in patients who had been treated by previous plating and the greatest number of vessels was formed in the patients who had been previously treated with the method of transosseous distraction osteosynthesis.

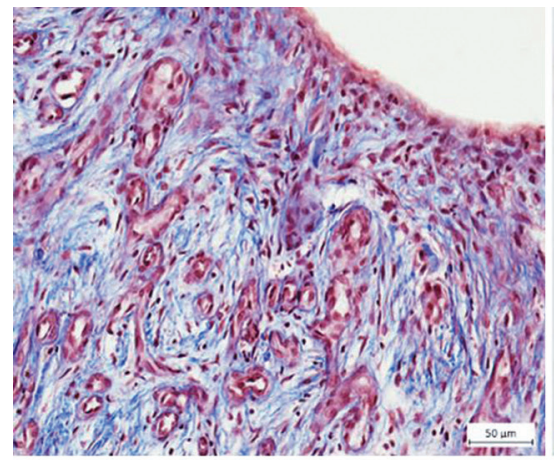

a

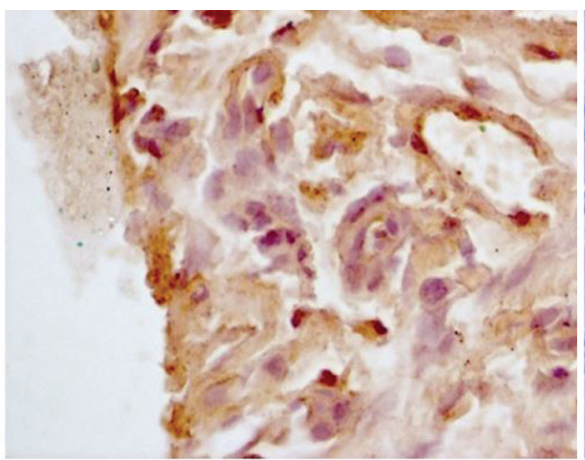

b

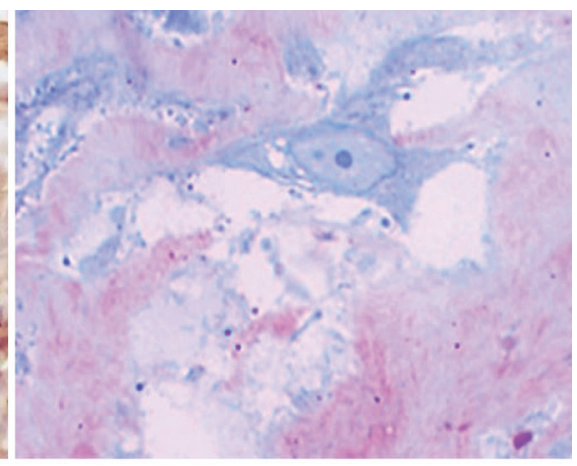

C

Fig. 1 Histostructure of biomembranes by the moment of spacer extraction: $\boldsymbol{a}$ double layer organization of membranes; Masson staining, magnification $400 \times$; b osteopontin expression in the biomembrane cells; histochemical reaction with antibodies against osteopontin; magnification $630 \times$; $c$ formation of PAS-positive matrix in the intercellular spaces; methylene blue stain with preliminary reaction; reagent Schiff stain; magnification $1200 \times$ 

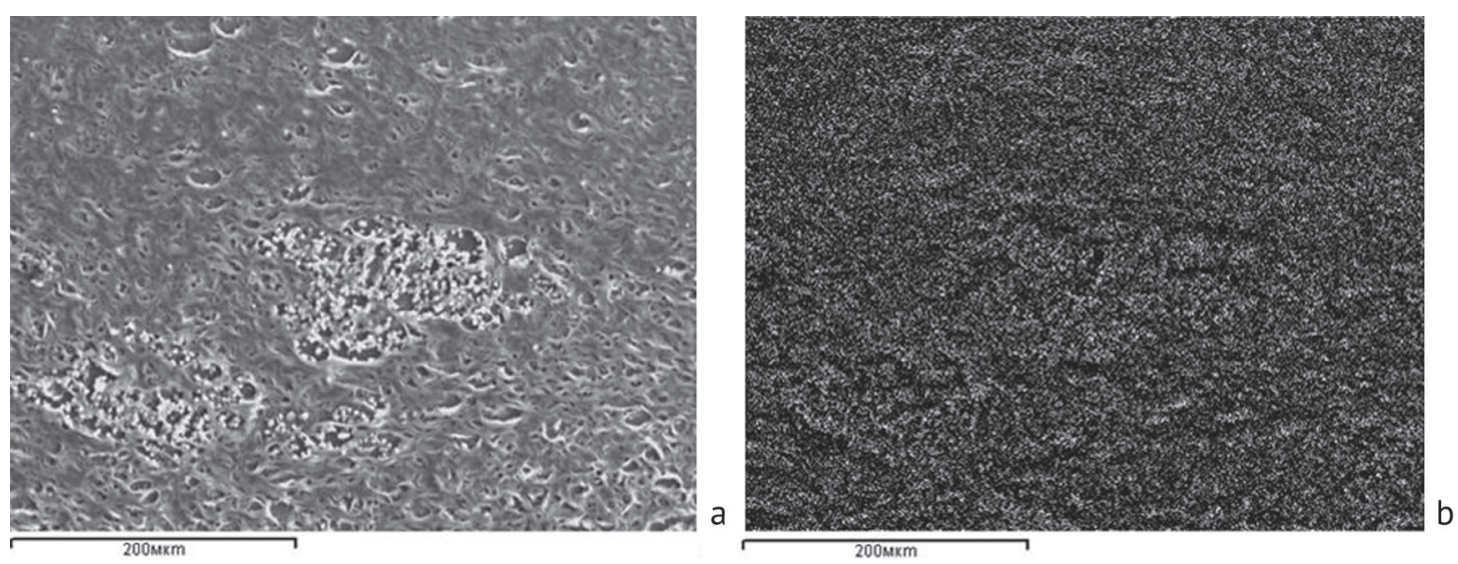

Fig. 2 Weak mineralization of the biomembrane: $\boldsymbol{a}$ scanning electron microscopy of the biomembrane; $\boldsymbol{b}$ distribution of $\mathrm{Ca}$ in the biiomembrane. Electronic mapping in characteritic roentgen radiation of Ca. Magnification $200 \times$

Neverheless, the number of microvessels formed was sufficient for osteoinductive effect of the biomembrane by formation of compression regenerate. Better blood supply in the new-periostium created optimal conditions for osteogenesis.

Case report A 19-year old patient who sustained an open left tibia fracture (Gustilo type III) in a traffic accident three years prior to admission had multiple treatment by plating and transosseous osteosynthesis at his residence hospital that failed and osteomyelitis developed. Infection was arrested one year before admission to our epartment. There was nonunion and 9-cm shortening of the left tibia. On admission, there were no signs of active infection and radiography revealed defect-pseudarthrosis in the lower third of the tibial diaphysis. The ends of fragments were noncongruent, oblique, eburnated and the bone marrow canal was obliterated (Fig. 3 a). There was a pronounced scarring, and scars were intimately adhered to the tibial fragments in the defect area and along the bone.
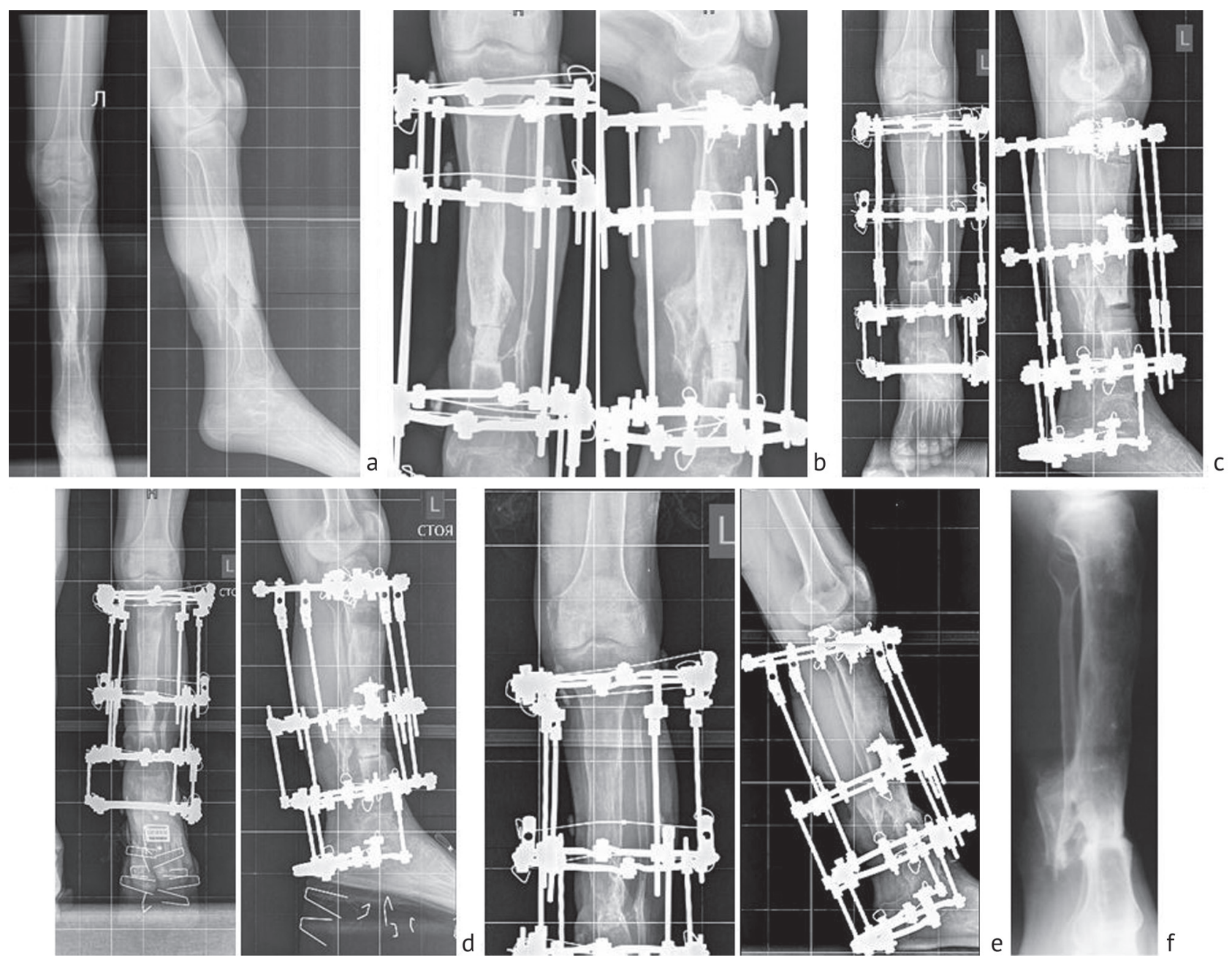

Fig. 3 Radiagraphs of the patient: $\boldsymbol{a}$ at admission; $\boldsymbol{b}$ after the firt stage; $\boldsymbol{c}$ at the second stage; $\boldsymbol{d}$ upon closed co-aptation of bone fragments; $\boldsymbol{e}$ before the Ilizarov fixator removal; $\boldsymbol{f}$ six months after the fixator removal 
At the first stage, the ends of the tibial fragments were treated and the defect area debrided, spacer implantation and the placement of the Ilizarov frame on the left tibia followed (Fig. $3 \mathrm{~b}$ ). The post-resection defect was $3 \mathrm{~cm}$. The wound healed with primary intention and stitching was removed after 14 days. The second stage was performed 27 dyas after and the spacer was removed (Fig, $3 \mathrm{c}$ ), osteotomy was performed in the upper third of the tibia, additional elements for fixation were attached and the frame was rearranged. Gradual distraction rate was $1 \mathrm{~mm}$ from post-operative day 5 and continued 54 days. The wound healed by primary intention. Fragments were adapted in a closed way (Fig. 3 d). The patient was discharged from the hospital for outpatient treatment that comprised suppotive compression at the junction of the fragments $1 \mathrm{~mm}$ every two weeks. Fixation in the frame was 125 days (Fig. 3 e). The fixator was removed at an outpatient department of our centre. Consolidation was achieved with residual shortening of $8 \mathrm{~cm}$. Ilizarov lengthening procedure has been planned (Fig. $3 \mathrm{f}$ ).

\section{DISCUSSION}

The authors of this study are followers of the Ilizarov non-free bone plasty for managing acquired bone defects and pseudarthrosis $[9,10]$.

We consider bone transport as an ideal type of bone plasty by which a vascularized autograft is transported in a dosed way within the soft tissues. Theoretically, it is possible to create the bone part of a required length and shape $[16,17]$. However, our opponents criticise this long and multi-stage treatment, possible soft-tissue infection around the wires, perforation of scars in the process of bone transport, and the risks of ischemic regeneration by distraction $[8,9,10,18]$.

Transport of fragments runs in particularly favourable conditions for reparative process if the combination of the Masquelet technique and the Ilizarov bone transport is used. After extraction of the spacer there is a tunnel in the interfragmental gap the walls of which are formed of the induced membrane. Bone transport is realized without difficulties within the compromised tissues which are debrided by the moment of distraction and without scars. The risk of infection around the wires is low; the danger of soft-tissue cutting or perforation with transported fragments is not high.

Apart from a favourable mechanical effect, the conditions modelled for bone transport provide a biological effect of the induced membrane on osteogenesis. Multiple microvessels of the biomembrane or neoperiostium that penetrate into the zone of compression regenerate promote the inflow of low differentiated pluripotent cells. The cells of the membrane basal layer and perivascular osteopontin-positive cells that possess ability to osteogenic differentiation contribute to formation of a low mineralized bone matrix on the surface of the spacer. It causes an osteoinductive effect on the pluripotent cells in the region of the compression regenerate formed.
Thus according to the reported data, it is known that the osteoinductive membrane is adequately vascularized and produces growth factors (VEGF, TGF-beta 1) and BMP-2 [1, 19]. There is an assumption that the induced membrane features antimicrobe activity related to the synthesis of antioxidant substances which are secreted locally along with growth factors. Another mechanism of a supposed bacteriostatic effect is presence of local peptides in the membrane which are able inhibit the secretion of the bacterial biofilm [20]. There were no focuses of infection in the biomembrane fragments in all the cases of its study.

The Ilizarov non-free bone plasty and the Masquelet technique have been used for extensive defects. According to several authors, the Masquelet technique advantage over the Ilizarov bone transport is related to treatment duration as the consolidation time does not depend on the defect size [21]. However, the deficit of the donor bone material will be inevitale in the management of large defects that requires to additionally use hydroxyapatite or tricalciophosphate bone substitutes, demineralized bone matrix (DBM) and demineralized bovine bone (DBB) along with cancellous bone grafts [22-24]. The use of free massive and combined in structure and composition implants, including in the conditions of the induced membrane formation, would not provide a full and completed organotypical remodelling of the bone tissue newly formed. This fact could probably explain high frequency of refractures in the patients in whom the Masquelet technique was used as compared with the results of the Ilizarov non-free bone plasty [11]. In the cases of associated soft tissue defects, their reconstruction requires plasty procedures if the Masquelet technique is used while the soft-tissue defect closure is provided by distraction histogenesis in the conditions of bone fragment transport [24]. 


\section{CONCLUSION}

The combined Masquelet technique and Ilizarov non-free bone plasty provide the conditions that are favorable for distraction and compression osteogenesis due to improved blood supply and osteoinduced effect of the biomembrane. Bone transport is carried out through debrided tissues not involved into scarring. There are low risks of inflammation around the transosseous elements; there is no danger of cutting and perforation of soft tissues by transported fragments.Complete organotypic rearrangement of the distraction regenerate with the use of Ilizarov non-free bone plasty and the Masquelet technique excludes the possibility of deformities or fractures at the level of newly formed bone areas. Active distraction histogenesis ensures the closure of soft tissue defects without additional reconstructive plastic interventions. The revealed dependence of the induced membrane blood supply on the treatment method previously used might be a criterion for predicting the treatment outcome in patients with acquired bone defects and pseudarthrosis managed with a combined use of the Ilizarov non-free bone plasty and Masquelet technique.

\section{REFERENCES}

1. Masquelet A.C., Begue T. The concept of induced membrane for reconstruction of long bone defects. Orthop. Clin. North Am., 2010, vol. 41, no. 1, pp. 27-37. DOI: 10.1016/j.ocl.2009.07.011

2. Borzunov D.Y., Gorbach E.N., Mokhovikov D.S., Kolchin S.N. Combined bone plasty interventions for rehabilitation of patients with congenital pseudarthrosis of the tibia. Genij Ortopedii, 2019, vol. 25, no. 3, pp. 304-311. (in Russian) DOI 10.18019/10284427-2019-25-3-304-311

3. Mokhovikov D.S., Stupina T.A., Varsegova T.N., Diuriagina O.V., Emanov A.A., Borzunov D.Yu. Histomorphometric characteristics of the tibialis anterior muscle and the peroneal nerve in experimental repair of post-resection tibial defect using the Ilizarov external fixation and the Masquelet technique. Genij Ortopedii, 2020, vol. 26, no. 2, pp. 216-221. (in Russian) DOI: 10.18019/1028-44272020-26-2-216-22

4. Stupina T.A., Diuriagina O.V., Emanov A.A., Mokhovikov D.S., Borzunov D.Yu. Pathomorphology of articular cartilage of the knee and ankle joints in experimental repair of postresection tibial defect using the Ilizarov method and cement spacer. Genij Ortopedii, 2020, vol. 26, no. 3, pp. 398-402. (in Russian) DOI: 10.18019/1028-4427-2020-26-3-398-402

5. Bernstein M., Fragomen A.T., Sabharwal S., Barclay J., Rozbruch S.R. Does integrated fixation provide benefit in the reconstruction of posttraumatic tibial bone defects? Clin. Orthop. Relat. Res., 2015, vol. 473, no. 10, pp. 3143-3153. DOI: 10.1007/s11999-015-4326-6

6. Ayouba G., Lemonne F., Kombate N.K., Bakriqa B., Yaovi Edem J., André-Piere Max U. Interest of nailing associated with the Masquelet technique in reconstruction of bone defect. J. Orthop., 2019, vol. 20, pp. 228-231. DOI: 10.1016/j.jor.2019.12.014

7. Morris R., Hossain M., Evans A., Pallister I. Induced membrane technique for treating tibial defects gives mixed results. Bone Joint J., 2017, vol. 99-B, no. 5, pp. 680-685. DOI: 10.1302/0301-620X.99B5.BJJ-2016-0694.R2

8. Paley D. Problems, obstacles, and complications of limb lengthening by the Ilizarov technique. Clin. Orthop. Relat. Res., 1990, no. 250, pp. 81-104.

9. Gubin A.V., Borzunov D.Y., Malkova T.A. The Ilizarov paradigm: thirty years with the Ilizarov method, current concerns and future research. Int. Orthop., 2013, vol. 37, no. 8, pp. 1533-1539. DOI: 10.1007/s00264-013-1935-0

10.Gubin A.V., Borzunov D., Malkova T.A. Ilizarov method for bone lengthening and defect management. Review of contemporary literature. Bull. Hosp. Jt. Dis., 2016, vol. 74, no. 2, pp. 145-154.

11.Mi M., Papakostidis C., Wu X., Giannoudis P.V. Mixed results with the Masquelet technique: A fact or a myth? Injury, 2020 , vol. 51, no. 2, pp. 132-135. DOI: 10.1016/j.injury.2019.12.032

12.Karger C., Kishi T., Schneider L., Fitoussi F., Masquelet A.C.; French Society of Orthopaedic Surgery and Traumatology (SoFCOT). Treatment of posttraumatic bone defects by the inducted membrane technique. Orthop. Traumatol. Surg. Res., 2012, vol. 98, no. 1, pp. 97-102. DOI: 10.1016/j.otsr.2011.11.001

13.Shevtsov V.I., Makushin V.D., Kuftyrev L.M. Defekty kostei nizhnei konechnosti. Chreskostnyi osteosintez po metodikam Rossiiskogo Nauchnogo Tsentra "VTO" imeni akademika G.A. Ilizarova [Defects of the Lower Limb Bones. Transosseous osteosynthesis according to the techniques of Russian Ilizarov Scientific Centre "Restorative Traumatology and Orthopaedics"]. Kurgan, Zaurale, 1996, 504 p. (in Russian)

14.Giannoudis P.V., Faour O., Goff T., Kanakaris N., Dimitriou R. Masquelet technique for the treatment of bone defects: tips-tricks and future directions. Injury, 2011, vol. 42, no. 6, pp. 591-598. DOI: 10.1016/j.injury.2011.03.036

15.Borzunov D.Y. Long bone reconstruction using multilevel lengthening of bone defect fragments. Int. Orthop., 2012, vol. 36, no. 8, pp. 1695-1700. DOI: 10.1007/s00264-012-1562-1

16.Green S.A., Jackson J.M., Wall D.M., Marinow H., Ishkanian J. Management of segmental defects by the Ilizarov intercalary bone transport method. Clin. Orthop. Relat. Res., 1992, no. 280, pp. 136-142.

17.Subasi M., A. Kapukaya. Distraction osteogenesis for treatment of bone loss in the lower extremity. J. Orthop Sci., 2003, vol. 8, no. 6, pp. 883-884. DOI: 10.1007/s00776-003-0728-5

18. Borzunov D.Y., Shastov A.L. Mechanical solutions to salvage failed distraction osteogenesis in large bone defect management. Int. Orthop., 2019, vol. 43, no. 5, pp. 1051-1059. DOI: 10.1007/s00264-018-4032-6

19.Pelissier P., Masquelet A.C., Bareille R., Pelissier S.M., Amedee J. Induced membranes secrete growth factors including vascular and osteoinductive factors, and could stimulate bone regeneration. J. Orthop. Res., 2004, vol. 22, no. 1, pp. 73-79. DOI: 10.1016/ S0736-0266(03)00165-7

20.Roukoz S., El Khoury G., Saqhbini E., Saliba I., Khazzaka A., Rizkallah M. Does the induced membrane have antibacterial properties? An experimental rat model of a chronic infected nonunion. Int. Orthop., 2020, vol. 44, no. 2, pp. 391-398. DOI: 10.1007/ s00264-019-04453-4

21.Lasanianos N., Kanakaris N., Giannoudis P. Current management of long bone large segmental defects. Orthopaedics and Trauma, 2010, vol. 24, pp. 149-163. 
Benij Ortopedii, Vol. 26, no 4, 2020

22.Masquelet A.C., Fitoussi F., Begue T., Muller G.P. Reconstruction des os longs par membrane induite et autogreffe spongieuse [Reconstruction of the long bones by the induced membrane and spongy autograft]. Ann. Chir. Plast. Esthet., 2000, vol. 45, no. 3, pp. 346-353. (in French)

23.Donegan D.J., Scolaro J., Matuszewski P.E., Mehta S. Staged bone grafting following placement of an antibiotic spacer block for the management of segmental long bone defects. Orthopedics, 2011, vol. 34, no. 11, pp. e730-e735. DOI: 10.3928/0147744720110922-16

24.Gupta G., Ahmad S., Mohd Z., Khan A.H., Sherwani M.K., Khan A.Q. Management of traumatic tibial diaphyseal bone defect by «induced-membrane technique». Indian J. Orthop., 2016, vol. 50, no. 3, pp. 290-296. DOI: 10.4103/0019-5413.181780

Received: 08.04.2020

\section{Information about the authors:}

1. Dmitry Yu. Borzunov, M.D., Ph.D.,

Ural State Medical University, Ekaterinburg, Russian Federation, Central City Clinical Hospital, Ekaterinburg, Russian Federation, Email: borzunov@bk.ru

2. Denis S. Mokhovikov, M.D., Ph.D.,

Ilizarov National Medical Research Centre for Traumatology and Orthopedics, Kurgan, Russian Federation

3. Sergey N. Kolchin, M.D., Ph.D.,

Ilizarov National Medical Research Centre for Traumatology and Orthopedics, Kurgan, Russian Federation

4. Elena N. Gorbach, Ph.D. of Biological Sciences,

Ilizarov National Medical Research Centre for Traumatology and Orthopedics, Kurgan, Russian Federation, Email: gorbach.e@mail.ru 